\title{
Os possíveis impactos do Sars-CoV-2 em gestantes e no desenvolvimento fetal: revisão narrativa
}

\author{
The possible impacts of Sars-CoV-2 on pregnant women and fetal development: a \\ narrative review
}
Los posibles impactos de Sars-CoV-2 en las mujeres embarazadas y el desarrollo fetal: una revisión narrativa

Maria Eduarda Melo Souza ${ }^{1 *}$, Ana Cláudia Ribeiro Farias ${ }^{1}$, Carlos Henrique França Vieira ${ }^{1}$, Felipe Santos Santana ${ }^{1}$, Camila Pinheiro Santiago Silva ${ }^{1}$, Wilian Reis Rosário ${ }^{1}$, Tatielle Gomes Dias ${ }^{1}$, Domingos Magno Santos Pereira ${ }^{1}$, Cristiane Santos Silva e Silva Figueiredo ${ }^{1}$, Caroline Amélia Gonçalves ${ }^{1}$.

\section{RESUMO}

Objetivo: Entender, a partir de uma revisão narrativa, os possíveis impactos do SARS-CoV-2 nas gestantes e para o desenvolvimento fetal. Revisão bibliográfica: Constatou-se que a maioria das gestantes desenvolveu algum tipo de sintoma da doença e a sintomatologia apresentada foi diversa, sendo febre e tosse as mais comuns. A progressão da COVID-19 em gestantes está associada a um processo de coagulopatia, com a maior possibilidade do desenvolvimento de coágulos intravasculares disseminados nos espaços intervilosos da placenta afetando as trocas gasosas e de nutrientes entre mãe e feto. Exames laboratoriais revelam que a proteína $C$ reativa pode estar aumentada, também os níveis elevados de enzimas hepáticas (TGO e TGP) e creatina fosfoquinase, dímero-D e troponina elevada. Não há informações consistentes para afirmar transmissão no binômio materno-fetal. Considerações finais: A sintomatologia de grávidas é semelhante à de não grávidas e não há evidências consistentes de infecção intrauterina causada por transmissão vertical em mulheres com SARS-CoV-2 no terceiro trimestre de gravidez.

Palavras-chave: Covid-19, Gravidez, Desenvolvimento fetal.

\begin{abstract}
Objective: To understand, from a narrative review, the possible impacts of SARS-CoV-2 on pregnant women and on fetal development. Bibliographic review: It was found that most pregnant women developed some type of symptom of the disease and the symptoms presented were diverse, with fever and coughing being the most common. The progression of COVID-19 in pregnant women is associated with a coagulopathy process, with a greater possibility of the development of disseminated intravascular clots in the intervillous spaces of the placenta, affecting the gaseous and nutrient exchanges between mother and fetus. Laboratory tests reveal that C-reactive protein may be increased, as well as elevated levels of liver enzymes (TGO and TGP) and elevated creatine phosphokinase, D-dimer and troponin. There is no consistent information to affirm transmission in the maternal-fetal binomial. Final considerations: The symptomatology of pregnant women is similar to that of non-pregnant women and there is no consistent evidence of intrauterine infection caused by vertical transmission in women with SARS-CoV-2 in the third trimester of pregnancy.
\end{abstract}

Keywords: Covid-19, Pregnancy, Fetal development.

\section{RESUMEN}

Objetivo: Comprender, a partir de una revisión narrativa, los posibles impactos del SARS-CoV-2 en las mujeres embarazadas y en el desarrollo fetal. Revisión bibliográfica: Se encontró que la mayoría de las mujeres embarazadas desarrollaron algún tipo de síntoma de la enfermedad y los síntomas que presentaron fueron diversos, siendo la fiebre y la tos los más comunes. La progresión de COVID-19 en gestantes se asocia

${ }^{1}$ Universidade CEUMA (UNICEUMA), Imperatriz - MA. *E-mail: madumelosouza@icloud.com 
a un proceso de coagulopatía, con mayor posibilidad de desarrollo de coágulos intravasculares diseminados en los espacios intervellosos de la placenta, afectando los intercambios gaseosos y de nutrientes entre madre y feto. Las pruebas de laboratorio revelan que la proteína $C$ reactiva puede estar aumentada, así como niveles elevados de enzimas hepáticas (TGO y TGP) y niveles elevados de creatinfosfoquinasa, dímero $D$ y troponina. No existe información consistente para afirmar la transmisión en el binomio materno-fetal. Consideraciones finales: La sintomatología de las mujeres embarazadas es similar a la de las mujeres no embarazadas y no hay evidencia consistente de infección intrauterina causada por transmisión vertical en mujeres con SARSCoV-2 en el tercer trimestre del embarazo.

Palabras clave: Covid-19, Embarazo, Desarrollo fetal.

\section{INTRODUÇÃO}

O ano de 2020 se iniciou com a divulgação do agente causador dos casos de pneumonia que se alastravam pela cidade de Wuhan, na China. A patologia é provocada pelo novo coronavírus, chamado cientificamente por Síndrome Respiratória Aguda Grave-Coronavírus e, em inglês, por Severe Acute Respiratory Syndrome-Coronavirus (SARS-CoV-2). Em questão de dias a doença se espalhou para o restante do mundo. No dia 30 de janeiro de 2020, a Organização Mundial da Saúde (OMS) declarou o surto de Doença Respiratória Aguda pelo SARS-CoV-2 como uma Emergência de Saúde Pública de Importância Internacional e todos os países foram obrigados a desenvolver ações para conter a transmissão do vírus e prevenir a disseminação (DASHRAATH P, et al., 2020).

Devido ao espectro clínico diverso, a doença do coronavírus 19 (COVID-19) varia de sintomas leves à síndrome respiratória aguda grave. Idosos e pessoas com comorbidades crônicas são as que mais apresentam complicações. O manejo clínico é voltado para o suporte e controle dos sintomas, haja visto que ainda não há um medicamento com eficácia comprovada para tratamento definitivo da doença. A partir disso é orientado realizar a detecção precoce da doença; manter o isolamento social para toda a comunidade; realizar a notificação, a investigação e o manejo adequado dos casos para evitar proliferação. É evidenciado que as principais vias de transmissão do SARS-CoV-2 são por meio de gotículas de secreções de vias respiratórias de indivíduos e superfícies contaminadas (CHEN H, et al., 2020; CARDOSO MVR, et al., 2020).

Em média, o período de incubação da doença ocorre entre 5 e 6 dias, podendo se estender por mais tempo em alguns casos. Quanto aos sintomas, os mais frequentes são a febre, tosse, coriza, congestão nasal, dispneia, mal-estar, mialgia, perda do paladar, sintomas gastrointestinais como diarreia, e até sintomas mais graves que levam a SARS-CoV-2. Vale destacar que há muitos casos de pessoas assintomáticas, o que pode dificultar na detecção e controle da doença. Fazem parte dos grupos com maior incidência da doença os idosos, imunossuprimidos, gestantes, puérperas e pessoas com comorbidades (CHEN H, et al., 2020; LIU J, et al., 2020). Mas destaca-se que, inicialmente, o número de gestantes infectadas era menor se comparado com o restante da população, porém, quando eram infectadas, apresentavam-se mais vulneráveis às manifestações mais agressivas da doença (CHEN H, et al., 2020; CARDOSO MVR, et al., 2020).

Com a disseminação da doença pelo mundo, o colapso dos serviços de saúde e os números de mortes subindo diariamente, pesquisadores de vários países se debruçaram na busca de drogas efetivas e seguras para o tratamento e controle da infecção pelo SARS-CoV-2. Diante deste cenário de incertezas e de buscas dos cientistas por meios que possam cessar a proliferação deste novo coronavírus, um grupo de pessoas tem ganhado atenção quanto aos efeitos desta nova doença: as gestantes. As grávidas representam um grupo da população com particularidades devido às alterações fisiológicas e imunológicas ocasionadas pela gestação. Também ainda há muitas incertezas quanto às características específicas do vírus e o que ele pode realmente causar ao binômio materno-fetal (CARDOSO MVR, et al., 2020; DONG L, et al., 2020; MASCARENHAS VH, et al., 2020).

Portanto, objetiva-se com este trabalho entender, a partir de uma revisão narrativa, os possíveis impactos da Covid-19 para as gestantes e para o desenvolvimento embrionário e fetal. Além de apontar as principais alterações em exames laboratoriais, clínicos e complicações que possam surgir durante a gravidez que apresente risco. 


\section{REVISÃO BIBLIOGRÁFICA}

As manifestações e ações do novo coronavírus no corpo humano podem aparecer de diversas formas, passando de leve e assintomático a casos graves. Neste contexto, as grávidas aparecem com destaque devido as condições particulares fisiológicas do corpo ao longo da gestação. Ressalta-se que a gravidez é um momento particular na vida da mulher e deve-se levar em consideração os riscos e benefícios maternos, fetais e neonatais (KWIATKOWSKI S, et al., 2020).

Em um estudo desenvolvido em Wuhan, na China, cidade onde o coronavírus foi diagnosticado pela primeira vez, analisou uma gestante de 29 anos com idade gestacional de 34 semanas e 2 dias, que apresentava quadro febril de $37,9^{\circ} \mathrm{C}$, congestão nasal, dispneia e tomografia computadorizada de tórax apresentando opacidade com padrão de vidro fosco na periferia de ambos os pulmões. Com relação aos exames laboratoriais, foram realizados o swab nasofaríngeo para RT-PCR, que deu positivo. Já o teste RTPCR para secreções vaginais apresentou valores negativos. O parto desta paciente foi cesariano de escolha e, depois de duas horas do nascimento, foram coletadas amostras de sangue do recém-nascido, sendo verificado os níveis de lgM e lgG positivos, as citocinas e leucócitos elevados e a tomografia computadorizada de tórax sem alteração (DONG L, et al., 2020; GUO YR, et al., 2020).

As alterações em exames complementares mais comuns são infiltrados bilaterais nos exames de imagem de tórax, linfopenia no hemograma e aumento da proteína C-reativa (DONG L, et al., 2020; GUO YR, et al., 2020). Para o diagnóstico laboratorial para identificação do vírus SARS-CoV-2 é necessária a realização de técnicas de biologia molecular como RT-PCR e/ou teste sorológico (teste rápido). As técnicas moleculares baseiam-se no princípio da detecção de sequências de RNA viral para SARS-CoV-2, enquanto os testes sorológicos buscam anticorpos humanos ( $\mathrm{lgG} / \mathrm{lgM}$ ) específicos contra o vírus (DONG L, et al., 2020; GUO YR, et al., 2020).

Em estudo na China, Ai T, et al. (2020) identificaram que os testes com ácido nucléico viral, por meio do RT-PCR, têm papel vital na decisão para hospitalizar e isolar determinado paciente, incluindo mulheres grávidas, mas a falta de sensibilidade, estabilidade insuficiente e tempo de processamento relativamente longo foram prejudiciais para o controle da doença. Além disso, os autores identificaram que vários fatores externos podem afetar os resultados deste tipo de exame, como: as operações de amostragem, fonte e tempo da amostra e desempenho de kits de detecção. Por conta disso, os autores recomendam que os resultados dos testes RT-PCR devem ser interpretados com cautela, mais ainda gestantes, visto a imunossupressão causada pelo período gestacional e as possíveis consequências para o feto.

Qu L, et al. (2020) publicaram um relato de uma mulher de 29 anos que teve contato com pessoa infectada com o novo coronavírus, apresentou sintomas leves e os primeiros testes de ácido nucleico (NAT) negativos. O exame físico não revelou sinais óbvios de pneumonia. Os exames de sangue de rotina mostraram contagem de leucócitos $\left(4.08 \times 109 / \mathrm{mm}^{3}\right)$, neutrófilos $(52,6 \%)$, linfócitos $(36,3 \%)$, contagem total de linfócitos (1.48 109 $\left./ \mathrm{mm}^{3}\right)$, proteína $C$ reativa rápida $(1,6 \mathrm{mg} / \mathrm{L})$ e proteínas amiloides séricas $(45,96 \mathrm{mg} / \mathrm{L})$. Todos os testes para detecção rápida de influenza $A$, influenza $B$, vírus respiratório-sincicial, pneumonia por micoplasma e adenovírus foram negativos. Dadas as características clínicas, registros epidemiológicos, achados de Tomografia Computadorizada (TC) e um terceiro NAT positivo, a paciente foi diagnosticada com Covid-19. Os autores relatam a importância da combinação de história de epidemiologia, sintoma clínico, tomografia computadorizada de pulmão e teste de sangue de rotina para um diagnóstico clínico de Covid-19 mais preciso, mesmo diante de pacientes assintomáticos ou com sintomas não comuns.

Jesus CVF, et al. (2020) em estudos com uma paciente de 19 anos, secundigesta, recepcionada na unidade de pronto atendimento (UPA) com 36 semanas de gestação, apresentava hipóxia, tosse, dispneia e febre, logo foi realizado teste rápido para COVID-19 e RT-PCR, apresentando resultado positivo para ambos. Com o agravamento do quadro para Síndrome Respiratória Aguda Grave por SARS-CoV-2, a paciente foi transferida para maternidade, onde foi realizada uma cesárea de urgência em decorrência do sofrimento fetal causado pela insuficiência respiratória da mãe. A mãe chegou ao óbito 10 dias após o parto pela progressão da doença, no entanto o recém-nascido foi internado em uma UTI neonatal, o que reflete diretamente 0 potencial danoso da infecção pelo SARS-CoV-2 em gestantes. 
Liang L e Acharya G (2020) publicaram algumas recomendações para grávidas diante da Covid-19 e ressaltam algumas alterações que essas pacientes podem apresentar ao contraírem o vírus, como a contagem de leucócitos periféricos normal ou diminuída; a contagem de linfócitos pode ser reduzida; proteína C reativa pode estar aumentada, podem apresentar níveis elevados de enzimas hepáticas e creatina fosfoquinase. Essas alterações podem ser comprovadas por meio de exames laboratoriais como o hemograma, Proteína C Reativa (PCR), Transaminase Oxalacética (TGO) e Transaminase Pirúvica (TGP) (LUGLIO M, et al., 2020).

A progressão da COVID-19 está associada a um processo de coagulopatia, com a maior possibilidade do desenvolvimento de coágulos intravasculares disseminados (CIVD) nos espaços intervilosos da placenta, devido a infecção levar a uma disfunção das células epiteliais intervilosas leva liberação de estimladores de agregação plaquetária, afetando as trocas gasosas e de nutrientes entre mãe e feto. Outros estudos encontraram forte correlação entre o aumento de Dímero-D plasmático e o pior prognóstico da doença. Os resultados mostram que as pessoas (incluindo mulheres grávidas) que morreram com a doença apresentaram as dosagens de Dímero-D acima da média do grupo de sobreviventes (SILVA MR, et al., 2020; BATSCHAUER APB e JOVITA HW, 2020; TANG N, et al., 2020).

Mascarenhas VHA, et al. (2020), ao analisarem 24 artigos sobre Covid-19 e gravidez, também destacaram como os principais sintomas apresentados pelas grávidas infectadas pelo novo coronavírus: febre, tosse seca, perda do paladar e dispneia; com alguns casos de diarreia, fadiga, mialgia, congestão nasal e coriza. Dentre os exames utilizados com mais frequência para identificação da Covid-19, os autores destacam: Reação em cadeia da polimerase com transcriptase reversa (RT PCR); Painel molecular de viroses respiratórias; Hemograma; Hemocultura; Proteína $C$ reativa; Provas de função hepática; Exames de imagem.

Ainda, segundo Mascarenhas VHA, et al. (2020), as principais complicações na gestação que as mulheres com Covid-19 apresentaram foram: aborto espontâneo; ruptura prematura de membranas; restrição de crescimento intrauterino; sofrimento fetal; e trabalho de parto levando ao parto prematuro. Sobre a transmissão vertical, os autores ressaltam que ainda não há evidências clínicas ou sorológicas para sugerir a possibilidade de haver transmissão vertical do vírus SARS-CoV-2, no entanto, relata que analisando amostras de líquidos amnióticos, sangue do cordão umbilical, swabs da faringe neonatal e esfregaços de leite materno detectaram ausência de isolados virais em todas essas amostras, sugerindo a ausência de transmissão intrauterina do vírus durante o terceiro trimestre, também analisaram material colhido da placenta após o parto, a fim de investigar uma possível transmissão transplacentária, e não demonstraram teratogenicidade, patologias e inflamações placentárias, presença do vírus SARS-CoV-2 ou disfunção tireoidiana no recémnascido.

Ao analisar dados clínicos de nove mulheres grávidas com Covid-19, Chen H, et al. (2020) identificaram que as características clínicas dessas pacientes foram semelhantes às de adultos não grávidas infectados pelo novo coronavírus. Os autores ressaltam que as mulheres grávidas são mais suscetíveis a patógenos respiratórios por conta do estado imunossupressor e as alterações adaptativas fisiológicas durante a gravidez. Os sintomas comuns das mulheres analisadas no estudo incluíram febre e tosse, enquanto os sintomas menos comuns foram mialgia, mal-estar, dor de garganta, diarreia e falta de ar. Os exames laboratoriais indicaram que a linfopenia também pode ocorrer. Além disso, concentrações aumentadas de ALT ou AST podem ser uma das manifestações clínicas. Os autores recomendam que exames clínicos relevantes devem feitos a fim de complementar o diagnóstico da patologia. Ao analisarem o líquido amniótico, o sangue do cordão umbilical e as amostras de esfregaço da garganta neonatal ao nascimento, os autores não encontraram evidências de transmissão vertical no final da gravidez.

Conforme Shah PS, et al. (2020) e Liang H e Acharya G (2020), a mulher pode ser infectada a qualquer momento durante a gravidez e o impacto no feto também pode variar conforme a período da gestação, sendo que no primeiro ou segundo trimestre a infecção pode causar aborto espontâneo, parto prematuro, defeitos congênitos ou outras infecções congênitas. Com relação a infecção materna no final da gravidez, o recémnascido pode apresentar infecção ativa e riscos adversos. Diante das dificuldades e da emergência de cuidados nesse cenário de pandemia. Shah PS, et al. (2020) desenvolveram uma proposta de classificação 
para diagnóstico de transmissão neonatal com o objetivo de auxiliar os profissionais de saúde na avaliação de pacientes e determinar medidas apropriadas de controle de infecção. A classificação é composta de cinco categorias mutuamente exclusivas da probabilidade de infecção: (a) confirmada, (b) provável, (c) possível, (d) improvável, e (e) não infectado. Sendo a primeira e a última categoria consideradas absolutas e confirmatórias.

A categoria provável indica forte evidência de infecção, mas falta de prova absoluta. Enquanto a categoria possível denota evidências que são sugestivas de infecção, mas são incompletas. Na categoria improvável são enquadrados os casos quando há pouco suporte para um diagnóstico, mas a infecção não pode ser completamente descartada. Pode, claramente, um caso ser inicialmente atribuído a uma categoria e, após coleta de mais informações, ser movido para outra categoria. Portanto, segundo esta classificação, é considerado infecção congênita neonatal somente quando são detectadas partículas virais no líquido amniótico antes do parto ou no sangue do recém-nascido (transmissão vertical) (SHAH PS, et al., 2020; LIANG H e ACHARYA G, 2020).

Em estudo sobre a transmissão vertical do novo coronavírus no binômio mãe-feto, Masmejan S, et al. (2020) analisou 13 pacientes com COVID-19. Foram analisados a placenta, sangue do cordão umbilical e a nasofaringe neonatal. Todos os neonatos tiveram PCR para SARS-CoV-2 negativos. Segundo os autores, os resultados e a alta proporção de resultados negativos entre recém-nascidos de mães infectadas indicam a raridade da infecção materno-placentária-fetal e a dificuldade de comprovação da transmissão vertical.

Em estudo semelhante, Yan J, et al. (2020) analisaram 116 pacientes grávidas diagnosticadas com COVID-19 e concluiu que houve oito casos de pneumonia grave, mas nenhuma morte materna. Além disso, 1 de 8 pacientes que apresentaram a doença no primeiro trimestre da gestação teve aborto espontâneo. A taxa de nascimento prematuro espontâneo antes de 37 semanas de gestação foi de 6 entre 99 pacientes. Outro achado relevante foi que 86 de 100 neonatos testados para SARS-CoV-2 tiveram resultados negativos. Os autores concluem não há evidência de transmissão vertical da infecção por SARS-CoV-2 quando a infecção se manifesta durante o terceiro trimestre da gravidez. Soma-se ao resultado que as características clínicas de mulheres grávidas com pneumonia por COVID-19 são semelhantes às de adultos não grávidas com a mesma patologia (YAN J, et al., 2020).

LIU W, et al. (2020) analisaram 19 neonatos (13 do sexo masculino e 6 do sexo feminino) de mães que foram diagnosticas clinicamente ou por laboratório com Covid-19. Os exames de RT-PCR do SARS-CoV-2 no swab da garganta, na urina e nas fezes dos recém-nascidos deram negativo. O leite materno e o líquido amniótico também foram examinados e deram negativo. Os autores relatam que nenhum sofrimento fetal foi encontrado. A idade gestacional dos neonatos era 38,6 $\pm 1,5$ semanas, e o peso médio ao nascer foi de 3293 $\pm 425 \mathrm{~g}$. Os neonatos também não desenvolveram evidências clínicas, radiológicas, hematológicas ou bioquímicas de Covid-19. Nenhuma transmissão vertical de SARS-CoV-2 e nenhuma complicação perinatal no terceiro trimestre foram encontradas no estudo.

Com relação aos resultados laboratoriais dos 19 neonatos após 24 horas de idade, os autores Liu W, et al. (2020) destacaram os seguintes resultados: contagem de glóbulos brancos $16.19 \times 10^{9} \mathrm{cells} / \mathrm{L}$, linfócitos $3.8 \times 10^{9}$ cells/L, neutrófilo $10,84 \times 10^{9}$ cells/L, plaquetas $295 \times 10^{9}$ cells/L, proteína $C$ reativa $1.2 \mathrm{mg} / \mathrm{L}$, alanina transaminase $10 \mathrm{IU} / \mathrm{L}$, aspartato transaminase $40 \mathrm{IU} / \mathrm{L}$, ureia $2,5 \mathrm{mmol} / \mathrm{L}$, creatinina $67 \mu \mathrm{mol} / \mathrm{L}$, o que mostra níveis elevados de leucócitos ativos e biomarcadores de lesão hepática e renal. 17 casos tiveram radiografia de tórax que mostrou normal e os 2 casos restantes mostraram aumento do pulmão marcação. Nenhum dos neonatos desenvolveu evidência clínica, radiológica, hematológica ou bioquímica de Covid-19. Além disso, os autores não identificaram transmissão vertical de SARS-CoV-2 e complicações perinatais no terceiro trimestre. Mas alertam que os recém-nascidos devem ser separados das mães infectadas e dos cuidadores para evitar contaminação externa.

Yang $P$, et al. (2020) também analisaram neonatos de mães diagnosticadas com Covid-19 no terceiro trimestre. Foram coletados e analisados prospectivamente as características clínicas, dados laboratoriais e resultados de 7 recém-nascidos de gestantes infectadas com SARS-CoV-2. 4 eram prematuros tardios com idade gestacional entre 36 semanas e 37 semanas, e os outros 3 eram bebês nascidos a termo. O peso médio 
constado no nascimento foi de $2.096 \pm 660 \mathrm{~g}$, e todos nasceram sem apresentar asfixia. Amostras de esfregaço faríngeo em 6 casos, líquido amniótico e sangue do cordão umbilical em 4 casos foram testados por RT-PCR, e não houve resultado positivo.

Com relação as gestantes identificadas com SARS-CoV-2, elas apresentaram febre, tosse e outros sintomas respiratórios, seguidos de dor abdominal, diarreia e outros sintomas gastrointestinais. Todas as 7 mulheres tiveram parto cesáreo e os neonatos passaram por exames laboratoriais que não demonstraram alterações substanciais. Os autores concluíram que os dados atuais demonstram que gestantes tardias com Covid-19 não causam eventos adversos graves em seus recém-nascidos, mas os recém-nascidos ainda apresentam alto risco de Covid-19 em condição de infecção pós-parto sem controle rigoroso da infecção hospitalar (YANG P, et al., 2020).

Ao analisar características epidemiológicas, manifestações clínicas, exames laboratoriais, tomografia computadorizada de tórax e desfechos da gravidez de 18 pacientes com Covid-19 tratados no Hospital Renmin da Universidade de Wuhan, Zhang L, et al. (2020), constataram resultados semelhantes e afirmam que a transmissão vertical do SARS-CoV-2 não foi detectada, mas a proporção de pneumonia bacteriana neonatal foi maior do que outras doenças neonatais em recém-nascidos. No entanto, as minorias das gestantes são assintomáticas, a maior parcela desenvolve sintomas na primeira semana de infecção, o que leva ao aumento do número de cesárias por indicação obstétrica, em decorrência das complicações gestacionais causadas pelo agravamento da infecção, já aqui relatadas (ZHANG L, et al., 2020; JESUS CVF, et al., 2020).

\section{CONSIDERAÇÕES FINAIS}

A partir dos trabalhos relatados nesta revisão, foi possível elucidar que as características clínicas da pneumonia por Covid-19 em mulheres grávidas foram semelhantes às relatadas por pacientes adultas não grávidas e que foram diagnosticadas com (SARS-CoV-2). Também não há evidências consistentes de infecção intrauterina causada por transmissão vertical em mulheres com SARS-CoV-2 no terceiro trimestre de gravidez. Com relação aos neonatos de mães com Covid-19, não se verificou complicações graves e alterações consideráveis nos exames laboratoriais. Mas ressalta-se que é vital prevenir a infecção e reduzir a possibilidade de exposição neonatal ao vírus, separando-o da mãe após o parto. Além disso, deve haver monitoramento conforme as diretrizes para intraparto e manejo do isolamento pós-parto.

\section{REFERÊNCIAS}

1. Al T, et al. Correlação dos testes de TC de tórax e RT-PCR na Doença do Coronavírus 2019 (COVID-19) na China: um relato de 1.014 casos. Radiologia, 2020; 296(2): 32-40.

2. BATSCHAUER APB, JOVITA H. Hemostasia e COVID-19: fisiopatologia, exames laboratoriais e terapia anticoagulante. Rev. Bras. An. Clin., 2020; 52(2): 138-142.

3. CARDOSO MEV, et al. COVID-19 na gestação: uma revisão integrativa. Revista Eletrônica Acervo Saúde, 2020; 12(10): 1-10.

4. $\mathrm{CHEN} \mathrm{H}$, et al. Clinical characteristics and intrauterine vertical transmission potential of COVID-19 infection in nine pregnant women: a retrospective review of medical records. The Lancet, 2020; 395.

5. DASHRAATH P, et al. Coronavirus disease 2019 (COVID-19) pandemic and pregnancy. American journal of obstetrics and gynecology, 2020; 222(6): 521-531.

6. DONG L, et al. Possible vertical transmission of SARS-CoV-2 from an infected mother to her newborn. JAMA, 2020; 323(18): 1846-1848.

7. GUO YR, et al. The origin, transmission and clinical therapies on coronavirus disease 2019 (COVID-19) outbreak - an update on the status. Military Medical Research, 2020; 7(1): 11-21.

8. JESUS CVF, et al. Gestante com COVID-19 submetida a cesariana por sofrimento fetal: primeiro relato de caso descrito no Brasil. Arquivos Catarinenses de Medicina, 2020; 49(2): 143-147.

9. KWIATKOWSKI S, et al. Why we should not stop giving aspirin to pregnant women during the COVID-19 Pandemic. Ultrasound Obstetrics Gynaecology, 2020; 55(6): 841-843.

10. LIANG H, ACHARYA G. Novel corona virus disease (COVID-19) in pregnancy: What clinical recommendations to follow? Acta Obstet Gynecol Scand, 2020; 99: 439-442. 
11. LIU J, et al. Overlapping and discrete aspects of the pathology and pathogenesis of the emerging human pathogenic coronaviruses SARS-CoV, MERS-CoV, and 2019-nCoV. Journal of Medical Virology, 2020; 92(5): 491-494.

12. LIU W, et al. Clinical characteristics of 19 neonates born to mothers with COVID-19. Front Med. 2020; 14(2): $193-198$.

13. LUGLIO M, et al. COVID-19 e danos ao fígado: revisão narrativa e protocolo clínico proposto para pacientes pediátricos em estado crítico. Clinics, 2020; 75: 1-7.

14. MASCARENHAS VHA, et al. COVID-19 and the production of knowledge regarding recommendations during pregnancy: a scoping review. Rev. Latino-Am. Enfermagem, 2020; 28: e3348.

15. MASMEJAN S, et al. Transmissão vertical e resultados materno-fetais em 13 pacientes com doença coronavírus 2019. Clinical Microbiology and Infection, 2020; 25(6).

16. QU L, et al. Repeated Nucleic Acid Tests Are Necessary for Early Diagnosis of Atypical COVID-19: A Case Report. Nano Life, 2020; 10(1): 1-6.

17. SHAH PS, et al. Classification system and case definition for SARS-CoV-2 infection in pregnant women, fetuses, and neonates. Acta Obstet Gynecol Scand, 2020; 99(5): 565-568.

18. SILVA MRF, et al. Dímero-d: fator limitante para o prognóstico de pacientes com covid-19. Revista Multidisciplinar em Saúde, 2020; 1(2): 76.

19. TANG N, et al. Anticoagulant treatment is associated with decreased mortality in severe coronavirus disease 2019 patients with coagulopathy. J Thromb Haemost, 2020; 18(5): 1094-9.

20. YAN J, et al. Doença por coronavírus 2019 em gestantes: relato baseado em 116 casos. American journal of obstetrics and gynecology, 2020; 223: 111e1-14.

21. YANG P, et al. Características clínicas e avaliação de risco de recém-nascidos de mães com COVID-19. Journal of Clinical Virology, 2020; 127: 104356.

22. ZHANG L, et al. Severe acute respiratory syndrome coronavirus 2 (SARS-CoV-2) infection during late pregnancy: a report of 18 patients from Wuhan, China. BMC pregnancy and childbirth, 2020; 20(1): 394. 